ISSN 2236-0859

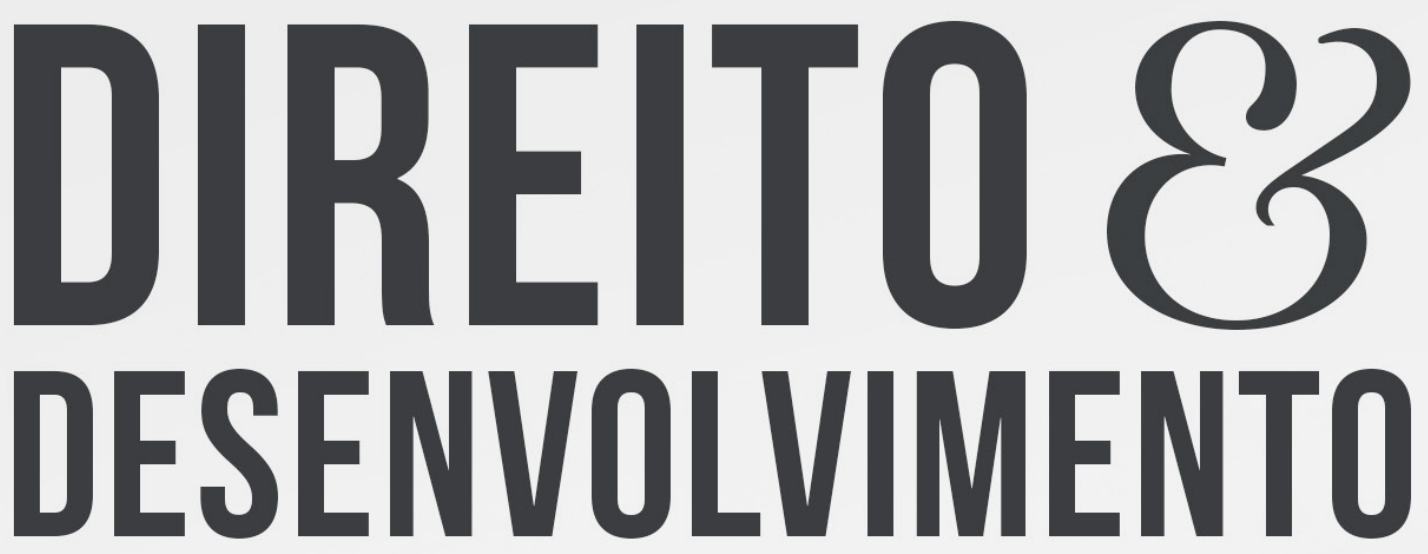

REVISTA DO PROGRAMA DE PÓS-GRADUAÇÃO EM DIREITO MESTRADO EM DIREITO E DESENVOLVIMENTO SUSTENTÁVEL

\title{
ACESSO À INFORMAÇÃO NO JUDICIIÁRIO: NECESSÁRIOS APRIMORAMENTOS PARA UMA ACCOUNTABLITY SOCIAL
}

ANNA LUISA WALTER DE SANTANA DANELLLE ANNE PAMPLONA 


\title{
ACESSO À INFORMAÇÃO NO JUDICIÁRIO: NECESSÁRIOS APRIMORAMENTOS PARA UMA ACCOUNTABILITY SOCIAL
}

\section{ACCESS TO INFORMATION IN THE JUDICIARY: NECESSARY IMPROVEMENT FOR A SOCIAL ACCOUNTABILITY}

Recebido: $12 / 06 / 2018$

Aprovado: 30/05/2019
Anna Luisa Walter de Santana ${ }^{1}$ Danielle Anne Pamplona ${ }^{2}$

\section{RESUMO:}

O artigo discute a necessidade de ampliação do acesso à informação no Judiciário, especialmente, no quesito intitulado transparência jurisdicional, como instrumento indispensável para a realização de um maior controle e monitoramento do Poder Judiciário no Brasil. Para tanto, fazendo uso do método hipotético-dedutivo, em um primeiro momento, é explorado o direito de acesso à informação e sua vinculação com o desenvolvimento da democracia e uma accountability social. Para em seguida, a partir de relatórios pesquisados, especialmente da ONG Artigo 19 e World Bank, analisar os pontos destacados para uma adequada transparência jurisdicional no Judiciário e seus pontos vulneráveis no Brasil. Identificou-se falhas importantes com relação ao acesso às informações jurisdicionais, que precisam de atenção e aprimoramento pelo Poder Judiciário, sob pena de graves prejuízos ao monitoramento e controle do órgão.

Palavras-chave: Acesso à informação. Poder Judiciário. Accountability social.

\begin{abstract}
:
The article discusses the need to expand access to information in the Judiciary, especially in the area of jurisdictional transparency, as an indispensable instrument for achieving greater control and monitoring of the Judicial Branch in Brazil. To do so, using the hypothetical-deductive method, is explored the right to access information and its link to the development of democracy and social accountability. Finally, from researched reports, especially from NGO art. 19 and World Bank, it analyzes the crucial points for an adequate judicial transparency in the Judiciary and its vulnerabilities in Brazil. Important shortcomings have been identified in relation to access to judicial information, which need attention and improvement by the Judiciary, under penalty of serious damage to the monitoring and control of the body.
\end{abstract}

Keywords: Access to information. Judicial Branch. Social accountability.

\footnotetext{
1 Doutoranda em Direito pela Pontifícia Universidade Católica do Paraná (PUC-PR), Mestre em Direito do Estado pela Pontifícia Universidade Católica de São Paulo (PUC-SP). E-mail: annaluisasantana@hotmail.com

2 Doutora em Direito pela Universidade Federal de Santa Catarina, Mestre em Direito pela Pontifícia Universidade Católica de São Paulo, Professora Titular da Pós-Graduação e da Graduação da Pontifícia Universidade Católica do Paraná. E-mail: dapamplona@ plamponaebraz.com.br
} 


\section{INTRODUÇÃO}

Diante do protagonismo do Poder Judiciário, o artigo se preocupada com as condições necessárias para uma accountability social do órgão. A accountability social, nos termos definidos por Peruzzoti e Smmulovitz (2006), é compreendida como uma ação coletiva e de ativismo cívico, em que os atores sociais compartilham a comum preocupação em melhorar o funcionamento das instituições. O envolvimento da população com aquilo que ocorre no Judiciário é fundamental para a legitimidade das decisões judiciais, para o desenvolvimento de um Judiciário mais eficaz e, especialmente, para a construção de um cidadão mais ativo e participativo na condução das grandes questões estatais.

O acesso às informações do Judiciário apresenta-se como condição primeira para a realização de um controle social no órgão. Não há que se falar em possibilidade de controle, se as informações a respeito do Poder não estiverem à disposição do cidadão. Tanto assim, que o acesso à informação pública sempre foi considerado um requisito indispensável para o próprio funcionamento da democracia, maior transparência e boa gestão pública. Em um sistema democrático representativo e participativo, a população exerce seus direitos constitucionais através da ampla liberdade de expressão e do livre acesso à informação.

Procurando responder se, atualmente, o Poder Judiciário garante um acesso à informação pleno e eficaz, com vistas a estimular uma maior accountability social, que o artigo se desenvolve. Fez-se uso do método hipotético-dedutivo de investigação e da pesquisa documental e bibliográfica, como método de procedimento. Em um primeiro momento, é explorado o direito de acesso à informação e sua vinculação com o desenvolvimento da democracia e uma accountability social. Por fim, a partir de relatórios pesquisados, especialmente da ONG Artigo 19 e World Bank, são analisados os pontos mais sensíveis para uma adequada transparência no Judiciário.

Optou-se pela análise da transparência jurisdicional do Poder Judiciário, tendo em conta que controle social proposto não deve se dar apenas no plano administrativo do Judiciário, mas também com relação a sua atividade-fim, isto é, a aplicação do próprio direito. A transparência administrativa é aspecto extremamente essencial não só para desenvolvimento dos mecanismos de controle da gestão pública, mas, para o desenvolvimento de uma necessária accountability social e de uma democracia verdadeiramente participativa. O critério da transparência jurisdicional é fundamental, pois é ele que permite que o cidadão conheça e se aproprie das atividades do Judiciário.

\section{ACESSO À INFORMAÇÃO COMO FERRAMENTA PARA O DESENVOLVIMENTO DA DEMOCRACIA E DA ACCOUNTABILITY SOCIAL}

A construção de uma sociedade democrática e de um cidadão participativo, que se aproprie das decisões estatais e seja capaz de realizar um controle crítico das atividades e dos serviços públicos, está assentada em uma série de esforços e estratégias. $\mathrm{O}$ artigo que se desenvolve a seguir, volta sua análise em umas dessas ferramentas que precisam estar à disposição do cidadão ativo, qual seja, o acesso à informação.

Para Lafer (1997) a transparência do público através de uma informação honesta e precisa é, portanto, condição para o juízo e a ação numa autêntica comunidade política. Tratase de assim de condição essencial para a manutenção de um espaço público democrático. Nesse sentido e em razão de sua relevância para o exercício da democracia, o direito à informação ultrapassa o âmbito individual e passa a ter caráter coletivo (DANTAS, GONÇALVES, 2016). 
Mesmo entendido como um direito humano fundamental, o direito à informação não possui nos tratados internacionais um artigo destacado e independente, mas decorre dos artigos que visam à proteção do direito à liberdade de expressão. Em sua primeira Assembleia Geral, mediante a adoção da resolução no 59(1), a Organização das Nações Unidas (ONU) declarou que o acesso à informação é um direito fundamental e pedra de toque de todas as liberdades às quais se dedica a organização. (ANGÉLICO; CRAVEIRO; MACHADO; MARTINS, 2017).

Trata-se de direito que decorre logicamente de outro direito fundamental: a liberdade de expressão.

\begin{abstract}
O entendimento de que o direito de acesso à informação decorre lógica e diretamente do direito à liberdade de expressão foi confirmado em diversas oportunidades. Nesse sentido, merecem destaque a Declaração de Chapultepec de 19942; os relatórios de 1995 e 1998 do Relator Especial para a Proteção e Promoção da Liberdade de Expressão e Opinião da ONU; a declaração conjunta de 1999 dos relatores especiais dedicados ao tema de liberdade de expressão da ONU, OSCE e OEA; e a declaração interamericana de princípios sobre liberdade de expressão adotada em 2000 pela Comissão Interamericana de Direitos Humanos (ANGÉLICO; CRAVEIRO; MACHADO; MARTINS, 2017. p 14).
\end{abstract}

No mesmo sentido, "las leyes de acceso a la información (LAI) contemporáneas surgen de las viejas batallas por las libertades de expresión, de prensa y por el derecho a participar en la toma de las decisiones públicas" (ACKERMAN E SANDOVAL 2005, pg. 17).

No âmbito do Sistema Regional Interamericano de Proteção aos Direitos Humanos, ao qual o Brasil se vincula, a temática do direito à informação, especialmente pública, e sua relevância para as sociedades democráticas já foi bastante explorado e consolidado.

Em um primeiro momento, o direito à informação foi reconhecido e destacado de maneira ampla na decisão do Caso Claude Reyes e outros vs. Chile de 20063. A Corte Interamericana de Direitos Humanos (CIDH) reconheceu a existência de um direito de acesso a informações oficiais, com base no art. 13 da Convenção Americana de Direitos Humanos, que dispõe sobre a liberdade de pensamento e de expressão. Isto porque, o direito à liberdade de pensamento e de expressão compreende não apenas o direito e a liberdade de expressar seu próprio pensamento, mas também o direito e a liberdade de buscar, receber e difundir informações e ideias de toda natureza.

Em seguida, um significante desenvolvimento do direito à informação, ocorreu em 2008, com a aprovação dos dez princípios sobre o direito de acesso à informação pelo Comitê Jurídico interamericano da Organização dos Estados Americanos (OEA), em que se reconhece a categoria de direito humano fundamental a ser aplicado a todos os órgãos públicos - Legislativo, Executivo e Judiciário. Já em 2010, foi aprovada pela Assembleia geral da OEA uma Lei Modelo sobre Acesso à informação Pública (PERLINGEIRO, 2016).

No caso Claude Reyes e outros vs. Chile de 2006, a Comissão Interamericana de Direitos Humanos afirmou que a divulgação da informação em poder do Estado desempenha um papel muito importante em uma sociedade democrática, pois habilita a sociedade civil a controlar as ações do governo a quem confiou a proteção de seus interesses e que o artigo 13 da Convenção deve ser compreendido como uma obrigação positiva de parte do Estado de oferecer acesso à informação em seu poder e reger-se pelo princípio de máxima divulgação. Portanto, o ônus da prova em situação de sigilo cabe ao Estado, o qual tem que demonstrar que as limitações ao acesso à informação são compatíveis com as regras interamericanas sobre liberdade de expressão.

No caso exposto, foi destacado ainda, o consenso regional dos Estados que integram a Organização dos Estados Americanos (incluindo o Brasil) sobre a importância do acesso à

3 Para maiores informações sobre o Caso Claude Reys vs Chile: www.corteidh.or.cr/docs/casos/articulos/seriec_151_esp.pdf 
informação pública e a necessidade de sua proteção. Isto porque, o acesso à informação pública é um requisito indispensável para o próprio funcionamento da democracia, maior transparência e boa gestão pública, e que em um sistema democrático representativo e participativo, a população exerce seus direitos constitucionais através da ampla liberdade de expressão e do livre acesso à informação.

Assim, a atuação do Estado, em todas as suas esferas e poderes, deve estar sempre regida pelos princípios de publicidade e transparência na gestão pública, o que faz possível que as pessoas que se encontram sob sua jurisdição exerçam o controle democrático da gestão estatal, de forma tal que possam questionar, indagar e considerar se está sendo realizado um adequado cumprimento das funções públicas.

Para que as pessoas possam exercer o controle democrático é essencial que o Estado garanta o acesso à informação de interesse público sob seu controle. Ao permitir o exercício desse controle democrático se fomenta uma maior participação das pessoas nos interesses da sociedade.

A Relatoria Especial para a Liberdade de Expressão da Comissão Interamericana ao tratar do direito de acesso à informação no Marco Jurídico Interamericano (2012) também reconhece o acesso à informação como uma ferramenta fundamental para a construção da cidadania, especialmente para a consolidação de sistemas democráticos nas Américas, possibilitando a participação de seus cidadãos em assuntos de interesse público.

A informação pública dá poder para que a sociedade lute contra abusos do Estado e proteja direitos. $\mathrm{O}$ acesso à informação é também ferramenta particularmente útil para o exercício dos direitos políticos e instrumento para a realização de outros direitos humanos.

De um lado, é ferramenta crítica para o controle e funcionamento do Estado e da gestão pública, por outro lado, é um meio para que, em um sistema democrático representativo e participativo, o povo possa exercer adequadamente seus direitos políticos. Isto porque, os direitos políticos têm como pressuposto um debate amplo e vigoroso para o qual é indispensável contar com a informação pública.

Es por ello que en la actualidad cabe decir, sintéticamente, que un sistema político democrático es aquel cuyo funcionamiento está basado en la participación consciente e informada de los ciudadanos en el ejercicio del poder político o bien indirectamente mediante la elección de sus representantes o bien directamente colaborando en la toma de decisiones políticas utilizando otros mecanismos (GALINDO AYUDA, 2012, p. 37)

Ainda segundo o Marco Jurídico Interamericano (2012), para garantir o efetivo direito de acesso à informação a gestão estatal deve reger-se pelos princípios da máxima divulgação e da boa-fé. A máxima divulgação exige que a transparência e o acesso à informação sejam a regra geral, submetida a estritas e limitada exceções. A boa-fé exige que a interpretação das leis crie uma cultura da transparência e assegurem o pleno exercício do direito.

Para Ackerman e Sandoval (2005) o direito à informação tem um impacto positivo em pelo menos três esferas de ação social: a política, a econômica e na administração pública. No âmbito político contribui para um despertar político dos cidadãos, de maneira que passam a participar mais ativamente das atividades governamentais. No âmbito econômico, permite investimentos com mais segurança, pois o mercado depende de um contínuo e confiável fluxo de informações. No âmbito da administração pública, a transparência melhora os processos de decisão e conduz a uma maior responsabilidade dos servidores públicos.

O direito de acesso à informação gera obrigações para todos as autoridades públicas, de todos os poderes e de todos os níveis de governo. Vincula também aqueles cumprem as funções públicas, prestam serviços públicos ou executem funções públicas em nome do Estado. 
Mesmo que reconhecida a importância do acesso à informação para o desenvolvimento da democracia e de um controle social acerca dos atos do Estado, a América Latina apresenta alguns deficits democráticos em termos de accountability ${ }^{4}$, especialmente porque os mecanismos tradicionais (eleições, separação dos poderes e o sistema de freios e contrapesos) se mostram incapazes de gerar a transparência e responsabilidade necessária (PERUZZOTTI; SMULOVITZ, 2006). Entretanto, muitos fatores - incluindo a proliferação de novas tecnologias de informação e comunicação - estão mudando a maneira como os cidadãos e a sociedade civil se envolvem com os governos e os serviços públicos.

Diante da dificuldade da efetividade de mecanismos de accountability vertical e horizontal5, Peruzzotti e Smulovitz (2016) expandem a noção de accountability vertical, para abarcar também elementos da sociedade civil (associações, ONGs, movimentos sociais) e da esfera pública (mídia, jornalismo investigativo), propondo a accountability social, a qual acaba por envolver ferramentas institucionais e não institucionais, sem estar presa ao calendário eleitoral.

\begin{abstract}
O espaço público de muitas das novas democracias está sendo gradualmente ocupado por uma nova geração de associações civis, ONGs, movimentos sociais e organizações da mídia organizadas em torno de uma política de accountability social. A política de accountability social representa uma das diversas formas de politização com base na sociedade civil presentes nas novas democracias. Como ressaltamos anteriormente, o conceito de accountability social faz referência a um conjunto diverso de ações e iniciativas civis guiadas por demandas de accountability legal. Esta nova forma de política que surge no espaço da sociedade civil engloba uma variedade de formas de ação coletiva e de ativismo cívico que compartilham uma comum preocupação em melhorar o funcionamento das instituições representativas através do fortalecimento dos mecanismos de controle da legalidade dos funcionários públicos (PERUZZOTTI, s.d. p. 5).
\end{abstract}

O que se espera, é que a accountability social, reforce os mecanismos de accountability vertical e horizontal, especialmente, de duas maneiras: indicando os déficits institucionais e forçando a ativação dos organismos através da pressão social e midiática (PERUZZOTTI, s.d.). Esse controle social proposto por Peruzzoti pode e deve envolver todas as esferas do governo e todos os poderes do Estado, já que o dever ser accountable atinge funcionário eleitos e não eleitos.

O direito de acesso à informação, como já afirmado anteriormente, também gera uma obrigação para todos os poderes estatais, isto porque quando a prática da disponibilização das informações não está incorporada no cotidiano estatal, a gestão da coisa pública fica prejudicada e o cidadão passa a não dispor de todos os meios possíveis para se tornar ativo na sua função social (NASCIMENTO, PARCA, 2016).

Além do mais, em sociedades democráticas a administração da justiça não pode ser isolada do contexto político e social em que seus atores atuam, ou acontecer sem os arranjos efetivos para a publicidade da sua operação administrativa e também jurisdicional. Assim, quase toda a informação produzida pelo Judiciário, como em qualquer outro poder estatal, pode ser requisitada por qualquer pessoa para a garantia de seu direito de acesso à informação pública e para controle do exercício do poder público no desempenho de suas funções (WORLD BANK, 2010).

4 A palavra accountability apresenta diversas significações, mas traz implicitamente a responsabilização pessoal pelos atos praticados e explicitamente a exigente prontidão para a prestação de contas, seja no âmbito público ou no privado. Apesar do significado possuir um sentido progressivo, todas as definições procuram garantir que o exercício do poder seja realizado, tão somente, a serviço da res publica. (PINHO; SACRAMENTO, 2009, pg. 134)

5 No sentido proposto por O'DONNEL, 1998. 
No Brasil, com a criação do Conselho Nacional de Justiça (CNJ), foram estabelecidas diversas ações para maior publicidade no Poder Judiciário. Essas ações que são obtidas pelo poder de accountability horizontal do órgão, permite ao povo e aos grupos da sociedade civil exercerem a accountability social sobre o Poder Judiciário (TOMIO; ROBL FILHO, 2013).

\footnotetext{
Com mais informações sobre orçamento, quantidade de processos apresentados e julgados, estrutura administrava e tantos outros dados fornecidos pelo CNJ, a população e grupos da sociedade civil podem discutir a atuação do poder Judiciário questionando se a independência judicial institucional está sendo bem utilizada para prestar uma jurisdição adequada e célere aos cidadãos, assim como possibilita analisar importantes elementos de accountability comportamental judicial (TOMIO; ROBL FILHO, 2013, p. 42).
}

Contudo, o acesso à informação judicial deve sempre assegurar a independência do Judiciário, assegurar uma justa administração da Justiça, promover uma administração eficiente, proteger a privacidade e segurança de juízes, partes e outros participantes dos processos judiciais, ao mesmo tempo em que assegura o acesso ao público e a imprensa daquilo que acontece no sistema de justiça (ARTIGO 19, 2016).

"Importante destacar que autonomia do Judiciário e accountability são noções que se complementam, na medida em que esta tem por finalidade legitimar aquela" (MARQUES FILHO; BARBOSA, 2016, p. 114 ).

\begin{abstract}
Diversamente dos demais países latino-americanos a questão a ser enfrentada não é se existe independência do Judiciário no Brasil, mas sim se o Judiciário não possui excesso de independência. Isso porque, tal excesso pode acarretar irresponsabilidade judiciária. Nesse contexto, é indispensável que o Judiciário tenha absoluta transparência e responsividade, medidas que são alcançadas pela accountability, daí decorrendo sua imprescindibilidade (MARQUES FILHO; BARBOSA, 2016, p. 114 ).
\end{abstract}

E é por meio do acesso à informação e da publicidade que se possibilita o exercício de accountabilities sociais no Judiciário (TOMIO; ROBL FILHO, 2013). O acesso a informação está dentro do próprio conceito de accountability, isto porque a accountability deve ser compreendida como um conceito relacional, que envolve a disponibilização de dados e informações, a criação de procedimentos que permitam a participação de cidadãos na ação política e no controle de seus resultados, e, de outro lado, estímulos orientados a transformação da postura passiva do cidadão em ativa (CLÉVE; FRANZONI, 2013).

O acesso à informação se torna a palavra-chave para a possibilidade de acompanhamento e monitoramento da população da atuação do Poder Judiciário. É ele que permite a compreensão da sociedade a respeito do funcionamento, desafios e limitações do Poder Judiciário, bem como viabiliza uma participação mais ativa do cidadão em aspectos substâncias do funcionamento do sistema de justiça, culminando com o aperfeiçoamento das instituições (WORLD BANK, 2010).

Importante destacar que, atualmente, quase nenhum tema de importância social deixa de ser apreciado pelo Judiciário, afastando o Judiciário da ideia de um poder puramente técnico e exigindo um processo de abertura e aproximação das cortes de seus jurisdicionados (ARTIGO 19, 2016). Para Kozicki e Araújo (2015) o Poder Judiciário é palco para a resolução de todo tipo de questão social relevante, que antes estavam fora do seu alcance, transferindo o poder das instituições representativas a órgãos judiciais.

Com esse papel de destaque ocupado pelo Poder Judiciário, o controle social proposto não deve se dar apenas no plano administrativo do Judiciário, mas também com relação a sua atividade-fim, isto é, a aplicação do próprio direito. 
Isto porque, em um regime democrático, o magistrado faz escolhas apenas em sua vida privada; já no âmbito do Poder Judiciário, suas decisões devem lançar argumentos de integridade e coerência, que emanam da própria comunidade política. O papel exercido pelo Poder Judiciário não elevou sua posição institucional a uma atuação totalmente arbitrária, livre de qualquer controle democrático (STRECK; TASSINARI; LIMA, 2013).

$\mathrm{O}$ acesso às informações com relação a atividade-fim do Judiciário é identificado, em pesquisas e relatórios que se dedicam ao estudo da temática do acesso à informação, com o nome de transparência jurisdicional. A transparência administrativa do Judiciário fica restrita aos dados de orçamentos dos tribunais, nomeações e salários, já a transparência jurisdicional está relacionada a informações sobre acesso ao sistema judicial; jurisprudência e andamento processual; audiências públicas e esferas de participação social; divulgação de pautas e agendas de audiências dos magistrados; informações sobre eleição de presidentes de tribunais; informações sobre designação de magistrados; informações sobre o processo de indicação e nomeação de ministros do Supremo Tribunal Federal (ARTIGO 19, 2016).

Diante da relevância que estas informações possuem para uma accountability social adequada e necessária do Poder Judiciário, que o artigo aborda a seguir, o atual estado da disponibilização das informações jurisdicionais e seus possíveis aprimoramentos.

\section{ACESSO À INFORMAÇÃO NO JUDICIÁRIO: NECESSIDADE E MECANISMOS}

O Poder Judiciário sempre foi considerado o Poder mais resistente a transparência, e embora no Brasil, a Constituição de 1988 respalde o direito à informação pública no art. $5^{\circ}$, inciso XXXIII, a garantia constitucional para a efetivação do direito à informação pública restringia-se ao habeas data previsto no inciso LXXII.

A regulamentação do acesso à informação veio só em 2011, no plano infraconstitucional, com a Lei 12.527, que entrou em vigor em maio de 2012, e ficou conhecida como LAI (Lei de Acesso a Informação). No Poder Judiciário a resolução para a implementação da LAI só foi ocorrer em 2015.

A regra passou a ser a transparência das informações públicas e o sigilo autorizado apenas em situações excepcionais. Todos os órgãos e entidades da administração pública direta e indireta devem cumprir os requisitos da LAI. A busca pela participação popular, pelo controle social e pelo livre acesso à informação pública foi coroada com a Lei de Acesso à Informação (ROMERO, SANT'ANNA, 2014).

Atualmente, são pelos critérios introduzidos pela LAI que se mede o acesso à informação e a transparência dos órgãos públicos.

A LAI abarca dois tipos de acesso à informação: a chamada transparência ativa, com o fornecimento de informações essenciais pelo Estado, independente de requerimento (art. $8^{\circ 6}$ ) e a transparência passiva, que permite a qualquer interessando e sem necessidade de motivação,

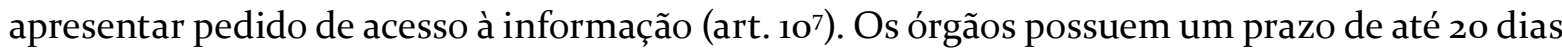
para a resposta.

No âmbito do Poder Judiciário, ficou o CNJ (Conselho Nacional de Justiça) responsável pela criação de uma resolução específica para os procedimentos jurídicos e para garantir o cumprimento da LAI pelo Judiciário.

6 BRASIL, Lei n. 12.527 de 18 de novembro de 2011. Art. $8^{\circ}$ : Art. 8: "É dever dos órgãos e entidades públicas promover, independentemente de requerimentos, a divulgação em local de fácil acesso, no âmbito de suas competências, de informações de interesse coletivo ou geral por eles produzidas ou custodiadas".

7 BRASIL, Lei n. 12.527 de 18 de novembro de 2011. Art. 10: "Qualquer interessado poderá apresentar pedido de acesso a informações aos órgãos e entidades referidos no art. $1^{\circ}$ desta Lei, por qualquer meio legítimo, devendo o pedido conter a identificação do requerente e a especificação da informação requerida”. 
Segundo o CNJ, mesmo antes da sanção da LAI, o órgão já adotava algumas medidas para tornar mais transparentes as atividades dos órgãos do Poder Judiciário. Em dezembro de 2009, a Resolução n.102 determinou que tribunais publicassem na Internet informações sobre a gestão orçamentária e financeira, quadro de pessoal e estrutura de remuneração de magistrados e servidores. Em 2010, a portaria n. 156, estabeleceu o prazo de três dias para as unidades do $\mathrm{CNJ}$ responderem às demandas da Ouvidoria do Órgão.

A Portaria n. 66 instituiu o Serviço de Atendimento ao Cidadão (SAC) com o objetivo de atender e orientar o público, informar sobre a tramitação de documentos e protocolizar requerimentos de acesso à informação, conforme determina o inciso I da Lei.

Mas, somente em 2015, o Conselho Nacional de Justiça (CNJ) publicou a Resolução n. 215, que determina a utilização de procedimentos objetivos e ágeis, de forma transparente, clara e em linguagem de fácil compreensão, a fim de garantir às pessoas naturais e jurídicas o direito de acesso à informação. A autoridade no âmbito do $\mathrm{CNJ}$ responsável pelo monitoramento e implementação da Lei de Acesso à Informação é o Ouvidor.

Segundo a Resolução n. 215, os órgãos administrativos e judiciais do Poder Judiciário devem garantir às pessoas naturais e jurídicas o direito de acesso à informação, mediante procedimentos objetivos e ágeis, de forma transparente, clara e em linguagem de fácil compreensão (art. $2^{\circ}$ ).

O acesso à informação deve seguir a regra geral da transparência; a divulgação de informações de interesse público, independentemente de solicitações; a utilização de meios de comunicação viabilizados pela tecnologia da informação; com vistas a fomentar o desenvolvimento da cultura da transparência na administração pública e contribuir para o desenvolvimento do controle social da administração pública.

O art. 6o da Resolução faz referência ao conteúdo mínimo que os sítios eletrônicos do Poder Judiciário deverão conter. Entre eles estão: finalidades e objetivos institucionais e estratégicos, metas, indicadores e resultados alcançados pelo órgão; dados gerais para o acompanhamento de programas, ações, projetos e obras desenvolvidos; audiências públicas realizadas e calendário das sessões colegiadas. Tudo em linguagem de fácil compreensão.

Para se verificar a transparência e acesso à informação no Poder Judiciário as pesquisas disponíveis, utilizando as recomendações da LAI, dividem a transparência do órgão em transparência administrativa e jurisdicional, como já explicitado anteriormente. O presente artigo dedica-se a verificar os resultados da transparência jurisdicional tão somente.

A transparência administrativa é aspecto extremamente relevante da LAI, para desenvolvimento dos mecanismos de controle da gestão pública e é normalmente a este quesito que se voltam as pesquisas. Mas, para o desenvolvimento de uma necessária accountability social e de uma democracia verdadeiramente participativa, o critério da transparência jurisdicional é fundamental, pois é ele que permite que o cidadão conheça e se aproprie das atividades do Judiciário. Nesse quesito são poucas pesquisas e o Judiciário, quando avaliado, apresenta resultados bastante insatisfatórios.

Além do mais, a maior parte das pesquisas encontradas ainda tem como enfoque principal a transparência administrativa do Judiciário, e poucas dedicam-se a chamada transparência jurisdicional. Seguindo os critérios do World Bank (2010) a Organização Art. 19, com sede em Londres e representação no Brasil, que anualmente acompanha a implementação da LAI no país, possui em seus relatórios espaço dedicado a transparência jurisdicional.

O relatório de 2016 da Artigo 19 faz a ressalva da dificuldade, muitas vezes, em se separar o que são informações administrativas e informações jurisdicionais. 


\begin{abstract}
Assim o é, por exemplo, quando o tema é a agenda de pautas e audiências, a designação de juízes, a eleição de presidentes de tribunais ou a indicação de ministros para cortes superiores. Esses temas, embora de aparente cunho organizativo-institucional, podem guardar significativo impacto sobre a concretização da Justiça. Temas que em princípio soam como meramente burocráticos podem ter importantes efeitos políticos (ARTIGO 19, 2016, p. 33).
\end{abstract}

O relatório do World Bank (2010), intitulado Access to Information and Transparency Judiciary, concentrou a análise da transparência jurisdicional nos seguintes pontos: publicidade das sentenças, acesso a arquivos e ações judiciais em caso de corrupção envolvendo funcionários públicos, transparência nas sessões dos Tribunais e mecanismos de participação da sociedade civil no Judiciário. O relatório aponta que diferentes arranjos são usados na América Latina para a promoção da participação do cidadão e deu destaque a transmissão das sessões dos tribunais pela rede de televisão, audiências públicas e a figura do amicus curie, todas já presentes no cotidiano do Judiciário brasileiro.

Com relação a publicidade das sentenças, especialmente das Supremas Cortes, o relatório destaca o impacto das decisões na proteção dos direitos dos cidadãos e que tal publicidade colabora para a supervisão, especialmente através da mídia, organizações da sociedade civil e academia, das atividades do Judiciário.

No que tange aos arquivos eações judiciais em caso de corrupção envolvendo funcionários públicos, o relatório aponta a frequência com que os casos de corrupção não são resolvidos de maneira eficiente no Judiciário e destaca mais uma vez a necessidade da participação dos jornalistas, ONGs e sociedade em geral para contribuir com uma maior transparência dessas ações e, indiretamente, reduzir a discricionariedade com a qual as investigações dos crimes de corrupção são gerenciadas.

No critério informação do trabalho desenvolvido nas Cortes Supremas o World Bank, destaca-se a necessidade da transparência dos processos distribuídos, evitando inclusive atrasos injustificados no julgamento.

Nos mecanismos para estimular a participação da sociedade civil, o relatório destaca o isolamento do Judiciário na América latina dos outros setores sociais. Mas diante da importância dos casos decididos, uma maior abertura se faz necessária. Boas práticas foram apresentadas nesse quesito e dizem respeito a gravação das sessões e canais de Justiça.

Foi feita referência a criação do Canal Judicial no México em 2006 após uma consulta nacional que indicou a necessidade do Judiciário de apresentar maior transparência em suas decisões. E no Brasil, apontou-se como uma boa prática a criação da Rádio Justiça em 2004 com o objetivo de realizar uma análise mais aprofundada das questões atuais relacionadas à justiça, tentando evitar o tratamento superficial que prevalece nos meios de comunicação de massa.

O relatório discorre a respeito das audiências públicas, que são verdadeiras lições cívicas a comunidade, e o amicus curiae, que segundo o relatório, é um mecanismo de participação cidadã que se transforma a busca pela justiça em uma atividade coletiva.

Eainda no quesito da participação civil, o relatório trata das iniciativas de monitoramento do Judiciário pela sociedade civil. Para o relatório, o crescente número de organizações civis, na déc de 80 , tiveram papel relevante na transição para os regimes democráticos. $\mathrm{O}$ Judiciário adquiriu especial relevância para a consolidação do Estado de Direito e seu funcionamento passa a interessar a sociedade civil. Destaque para a ONGs que não só monitoram, avaliam e examinam o desempenho do Poder Judicário, mas contribuem significativamente com propostas de reforma e modernização destinadas melhorar, entre outros, a sua transparência, eficácia e acessibilidade. 


\begin{abstract}
The judicial observatories and citizen oversight organizations are only a few of the numerous initiatives driven by civil society to monitor the operation of the justice system in the region. 52 The existence of long term projects designed to monitor the Judiciary has the double role of establishing a sort of ongoing "control" over its performance and generating specific information about it. (WORLD BANK, 2010, p. 32,33).
\end{abstract}

Os destaques de boa prática foram para o Projeto de Auditoria Social do Sistema de Justiça do Peru, que envolve universidades e tribunais peruanos, criado pela Comissão Andina de Juristas e o Consórcio Justiça Viva, um esforço destinado a monitorar a situação do Judiciário, ambos no Peru. Os observatórios da Justiça Constitucional na Colômbia, do Sistema Judicial no Uruguai e da Democracia e Governança na Nicarágua foram apontados como verdadeiras auditorias sociais, que tem o objetivo comum de melhor a qualidade da administração da Justiça.

Já no Brasil, o relatório de 2016, Caminhos da Transparência da ONG Artigo 19, em comemoração aos quatro anos da LAI, aponta o Judiciário como o mais opaco, em termos de acesso à informação, dos três Poderes no Brasil.

No que tange a transparência jurisdicional o relatório trabalhou com temas sobre os quais a maior abertura da Justiça poderia ser observada, sendo eles informações sobre: acesso ao sistema judicial; jurisprudência e andamento processual; audiências públicas e esferas de participação social; divulgação de pautas e agendas de audiências dos magistrados; eleição de presidentes de tribunais; designação de magistrados; e o processo de indicação e nomeação de ministros do Supremo Tribunal Federal.

Para a ONG Artigo 19 (2016) os desafios relacionados à transparência na atividade jurisdicional são muitos e multifacetados e vislumbra-se no Brasil a necessidade de aprimoramento tanto da transparência passiva quanto da transparência ativa.

A fim de tocar no tema da transparência no que tange ao acesso à Justiça, foi analisada a existência (ou não) - por via de transparência ativa - de orientações que vão além dos telefones e contatos dos tribunais. Procurou-se, objetivamente, as informações simplificadas de acesso à assistência judiciária, gratuita ou não, e as instruções para ingressar com uma ação judicial ou se defender de uma. Em relação à disponibilização de informações claras sobre como ingressar com uma ação judicial, só foi possível encontrar esse tipo de dado em dois portais: o TJ de Minas Gerais e o TJ de Roraima possui uma seção voltada a informações de "interesse público". Nos outros tribunais, não foi possível verificar informações de fácil acesso e que expressassem com clareza as formas de acesso à Justiça por parte do cidadão

Com relação ao tópico: Jurisprudência e andamento de processos, buscou-se uniformizar o sistema de buscas a partir de uma resolução do Conselho Nacional de Justiça, que contém uma lista de informações (como dados gerais do processo e das partes, salvo em caso de segredo de justiça, além de informações sobre decisões que forem tomadas no curso do processo) que devem ser disponibilizadas para qualquer pessoa que acesse o sistema, sem restrições. Os tribunais não são obrigados a divulgarem a íntegra dos processos digitais, de forma que, em todos os 27 portais dos Tribunais de Justiça, ela só pode ser acessada por pessoas que estejam diretamente ligadas ao caso e seus advogados, ou por advogados com número da OAB cadastrado nos sites, o que burocratiza muito o acesso.

O critério participação popular, obteve resultado bastante insatisfatório. Trata-se de critério fundamental para uma maior participação do povo nos processos judiciais, com a intenção de prestar-lhes mais legitimidade, além do mais é um dos poucos instrumentos disponíveis no país com essa intenção. O critério tem sido objeto de monitoramento por parte da ARTIGO 19 já há algum tempo, também em relação aos demais poderes em relatórios anteriores. 
As informações buscadas que compõem esse critério são aquelas que auxiliam o cidadão a participar ou a acompanhar os mecanismos decisórios do órgão em questão, tais como a divulgação de audiências e consultas públicas.

\begin{abstract}
Seguindo a tendência das últimas análises, o resultado verificado é que esse se trata de um dos critérios menos prestigiados nos Tribunais de Justiça, já que apenas sites de três estados - Goiás, Maranhão e Minas Gerais - apresentaram essas informações. Como ressaltado anteriormente, essa constatação é bastante negativa, à medida que, com o aumento de demanda pela ação do Judiciário em questões que vão além da resolução de conflitos individuais, a realização de audiências e consultas públicas, e sua divulgação para o público, são essenciais para que a sociedade possa participar ativamente das discussões, bem como para tornar mais transparentes os fundamentos utilizados pelo juiz para tomar suas decisões (ARTIGO 19, 2016, pg. 36).
\end{abstract}

A disponibilização de informações de forma proativa, de mecanismos de incentivo à participação popular, é uma exigência expressa da LAI. O Art. 9º da Lei de Acesso à Informação estabelece que o acesso a informações públicas será assegurado mediante a criação de serviço de informações ao cidadão, a realização de audiências ou consultas públicas, e o incentivo à participação popular.

Para a ONG, um elemento que não deixa também de se inserir no contexto de participação popular, é a publicação das pautas dos julgamentos semanais e a construção de uma agenda de trabalho dos magistrados que seja divulgada ao público. Trata-se da forma com que cidadãos e organizações sociedade civil possam manter contato direto com o funcionamento da Justiça. A maioria dos TJEs disponibiliza a informação para fácil acesso, mas a impossibilidade de encontrar os dados em sete deles ainda é preocupante, uma vez que as audiências e os julgamentos são públicos e interessam não apenas às partes, mas a todo cidadão que deseje conhecer os trabalhos da Justiça.

No critério ascensão e alocação dos magistrados a ONG mandou pedidos de informação para os 27 Tribunais de Justiça do Brasil, requerendo esclarecimentos sobre o procedimento de escolha dos presidentes de cada TJ. Destes pedidos, 10 não foram respondidos. Entre os restantes, mais de metade teve a resposta classificada como acesso parcial. O processo de escolha do presidente dos Tribunais de Justiça, em grande parte, acontece por meio de eleições. Entretanto, os critérios de elegibilidade, que faziam parte dos pedidos de informação protocolados, não foram explicados, constituindo um ponto sensível da análise.

Segundo o Relatório (ARTIGO 19, 2016) o Judiciário, tem sido visto historicamente como o Poder mais fechado e opaco, distanciando-se daqueles que buscam sua atuação para a proteção de direitos e novos olhares sobre o papel do Judiciário têm exigido cada vez mais que as cortes assumam o impacto político de suas decisões. E embora, nos últimos anos, tenhase percebido avanços relacionados à transparência no Judiciário, o caminho adiante ainda é muito longo.

Nossa análise sobre a implementação da LAI e da Resolução no 215 do CNJ nos TJs demonstrou que as cortes ainda estão muito aquém das expectativas cinco anos após a aprovação da LAI. O dado mais alarmante foi a porcentagem de não respostas, que ultrapassou $50 \%$ dos pedidos enviados. Entre as solicitações respondidas, a qualidade dos retornos também foi uma preocupação, com apenas $29,6 \%$ considerados satisfatórios e completos. Esse dado é especialmente inquietante se levarmos em consideração que os pedidos enviados eram simples e objetivos, relacionados basicamente a como os tribunais se adaptaram aos dispositivos da LAI. No campo da transparência ativa, vale ressaltar que nenhum dos TJs cumpriu todos os requisitos verificados, sendo que eles são exigências diretas do texto da LAI e da resolução. Outro desafio diz respeito à linguagem essencialmente jurídica utilizada pelos órgãos verificada tanto na análise da 
transparência passiva quanto na da transparência ativa, o que dificulta o entendimento das informações divulgadas e a interlocução dos cidadãos com os órgãos do Judiciário (ARTIGO 19, 2016, pg. 45)

Outra pesquisa realizada também pela ONG Art. 19 e FGV, intitulada Desafios da Transparência no Sistema de Justiça Brasileiro de 2017, também apresenta conclusões semelhantes. No âmbito jurisprudencial, verificou-se a existência de um mecanismo público de busca dos assuntos segundo sua normativa legal e foi verificado o formato no qual estão disponíveis os arquivos que contenham tais informações e qual o nível de detalhamento destas sentenças. O Conselho Nacional de Justiça (86\%) foi o melhor avaliado, seguido do Conselho Nacional do Ministério Público (CNMP) (8o\%), e Tribunal Superior Eleitoral (72\%). Na outra extremidade, estão o Ministério Público do Trabalho (33\%) e o Supremo Tribunal de Justiça (41\%).

Acategoria "publicação da programação deaudiências" visa levantar se há disponibilidade do agendamento de audiências nos portais de cada um dos órgãos que compõem a amostra. Nesse sentido, foi verificado se o órgão publica pelo menos a agenda semanal. Em tal categoria, o desempenho foi muito ruim em todos os órgãos analisados, com exceção do CNMP.

Com relação a disponibilização da agenda das atividades previstas para os juízes e seus correspondentes no Ministério Público, apenas o CNMP e o Superior Tribunal Militar atendem parcialmente a esse item. Os demais órgãos não atenderam sequer a um dos quesitos formulados.

Linguagem inacessível, arquivos em formato PDF e mecanismos de buscas muito complexos são constatações repetidas em todas as pesquisas. As pesquisas mostram que o Judiciário está longe da transparência que a legislação exige e a sociedade almeja.

De certa forma, temos uma grande contradição em causa. Se por um lado o Poder Judiciário resiste bravamente a mudanças significativas em seu ethos decisório moroso e elitista, de outro percebe-se uma mudança expressiva na sociedade, fruto da alteração da tradicional contraposição eixo público versus privado para uma perspectiva mais interacional, podendo implicar numa (re)definição dos tradicionais conceitos estanques para uma nova ordem no campo dos direitos e das correspondentes tutelas coletivas" (TAVARES NETO; BARBOSA, 2012, p. 70)

Para Michener; Moncau e Velasco (2016) os obstáculos ao cumprimento da LAI por parte do Poder Judiciário em são de três tipos. Burocráticos: são aqueles referentes ao processo de acesso à informação, como a forma de encaminhamento do pedido, aos requisitos para envio ou à identificação do órgão/departamento responsável pelo recebimento dos pedidos, entre outros; Jurídicos ou de interpretação, que são relativos aos fundamentos legais para o indeferimento dos pedidos, ou à ampla interpretação das exceções ao direito de Acesso à Informação contidas na LAI; e os técnicos ou de processamento de informação - relativos aos formatos ou padrões de agregação das informações solicitadas, que eventualmente possam prejudicar a visualização ou o processamento da informação requerida.

No que se refere a transparência jurisdicional, o caminho que precisa ser percorrido ainda é longo e os ajustes inúmeros. Contudo, a América Latina, apresenta boas práticas daquilo que o World Bank intitulou de verdadeiras auditorias sociais, que poderiam servir de exemplo para o judiciário Brasileiro. Certamente, esses exemplos poderiam contribuir para a necessária accountability social no Brasil, especialmente, diante do protagonismo judicial dos últimos anos. 


\section{CONCLUSÃO}

A construção de uma sociedade democrática e de um cidadão participativo, que se aproprie das decisões estatais e seja capaz de realizar um controle crítico das atividades e dos serviços públicos, está assentada em uma série de esforços e estratégias. Uma das ferramentas que precisam estar à disposição do cidadão ativo é o acesso à informação.

Embora esses mecanismos de controle das atividades públicas apresente um déficit em toda a América Latina, os espaços públicos de muitas das novas democracias vêm sendo ocupado por uma nova geração de associações civis, ONGs, movimentos sociais e organizações da mídia organizadas em torno de uma política de monitoramento e preocupação com eficiência das instituições, denominada de accountability social.

O do Poder Judiciário, na medida em que se envolve na resolução de todo tipo de questão social relevante, também precisa estar mais aberto e passível de um controle social. Respeitando a independência judicial, o controle social proposto não deve se dar apenas no plano administrativo do Judiciário, mas também com relação a sua atividade-fim, isto é, a aplicação do próprio direito.

Para que a accountability social acontece no âmbito do Judiciário, o acesso às informações do órgão, tanto administrativas quanto jurisdicionais, precisam ser claras e eficientes. Os critérios utilizados para se verificar a qualidade da transparência no Poder Judiciário e se o acesso à informação é adequado, são os critérios estabelecidos pela Lei de Acesso à Informação, que regulamentou o direito no país.

No mais, o Poder Judiciário, em 2015, através do Conselho Nacional de Justiça (CNJ) publicou a Resolução n. 215, que determina a utilização de procedimentos objetivos e ágeis, de forma transparente, clara e em linguagem de fácil compreensão, a fim de garantir às pessoas naturais e jurídicas o direito de acesso à informação.

No que tange a transparência jurisdicional, relacionada a atividade-fim do Judiciário, fundamental para uma accountability social, pode-se concluir, pelas pesquisas analisadas que o Judiciário brasileiro ainda apresenta resultado bastante insatisfatório.

Pontos, como acesso ao sistema judicial; jurisprudência e andamento processual; audiências públicas e esferas de participação social; divulgação de pautas e agendas de audiências dos magistrados e eleição de presidentes de tribunais, precisam de significativa evolução. Para a ONG Art. 19, que analisou o acesso à informação jurisdicional dos TJs no país, as cortes ainda estão muito aquém das expectativas cinco anos após a aprovação da LAI.

As pesquisas mostram que o Judiciário está longe da transparência que a legislação exige e a sociedade almeja. Se o acesso à informação não se tornar pleno e eficiente, a accountability social, desejada e necessário no Poder Judiciário, também se apresenta prejudicada.

O acesso à informação não é condição única para o desenvolvimento da accountability social, mas certamente é condição primeira e exige mais esforços por parte do Poder Judiciário para sua total satisfação.

\section{REFERÊNCIAS}

ACKERMAN, John M.; SANDOVAL, Irma E. Leyes de Acceso a la Información en el mundo. Cuadernos de Transparencia, n. 07. Delegación Coyoacán, México, D.F.: Instituto Federal de Acceso a la Información Pública, 2005. Disponível em: http://www.resi.org.mx/icainew_f/ images/Biblioteca/Cuaderno\%2otransparencia/cuadernillo7.pdf. Acesso em: 20 de julho de 2017. 
ANGÉLICO, Fabiano; CRAVEIRO, Gisele; MACHADO, Jorge; MARTINS, Paula (org.) Desafios da Transparência no Sistema de Justiça Brasileiro, 2 ed. rev., São Paulo: 2017.

ARTIGO 19, Caminhos da Transparência: A lei de Acesso à informação e os Tribunais de Justiça, 2016. Disponível em: http://artigo19.org/wp-content/blogs.dir/24/files/2016/o5/ ARTIGO-19-Caminhos-da-Transpar\%C3\%AAncia-\%E2\%80\%93-A-Lei-de-Acesso-\%C3\%AoInforma $\% \mathrm{C}_{3} \% \mathrm{~A}_{7} \% \mathrm{C}_{3} \% \mathrm{~A}_{3}-\mathrm{e}-\mathrm{e}-\mathrm{os}_{-T r i b u n a i s-d e-J u s t i} \mathrm{C}_{3} \% \mathrm{~A}_{7}$ a.pdf. Acesso em: 10 de julho de 2017.

BRASIL, Constituição da República Federativa do Brasil de 5 de outubro de 1988. Disponível em: http://www.planalto.gov.br/ccivil_03/Constituicao/ConstituicaoCompilado.htm. Acesso em 20 de julho de 2017.

BRASIL, Lei n. 12.527 de 18 de novembro de 2011 (Lei de Acesso à Informação). Disponível em: http://www.planalto.gov.br/ccivil_03/_ato2011-2014/2011/lei/l12527.htm. Acesso em: 20 de julho de 2017.

CEPIK, Marco. Direito à Informação: situação legal e desafios. Informática Pública, Belo Horizonte, vol 02, n. 02, p.43-56, 2000.

CLÉVE, Clémerson Merlin; FRANZONI, Julia Ávila . Administração Pública e a nova Lei de Acesso à Informação. Interesse Público. Belo Horizonte, v. 15, n. 79, p. 15-40, maio/jun. 2013.

CONSELHO NACIONAL DE JUSTIÇA, Resolução n. 215 de 16 de dezembro de 2015. Disponível em: http://www.cnj.jus.br/busca-atos-adm?documento=3062. Acesso em: 20 de julho de 2017.

DANTAS, Andressa de Bittencourt Vieira; GONÇALVES, Camila Figueiredo Oliveira. Liberdade de expressão e direito à informação: os limites da atividade jornalística sob a ótica do STF e do STJ. Revista Opinião Jurídica, Fortaleza, v. 14, n. 18, p. 89-118, 2016.

GALINDO AYUDA, Fernando. Democracia, internet y gobernanza: una concreción. Sequência, Florianópolis, n. 65, p. 33-56, dez. 2012. Disponível em <http://www.scielo.br/ scielo.php?script=sci_arttext\&pid=S2177-70552012000200003\&lng=pt\&nrm=iso $>$. Acesso em 23 jul. 2017. http://dx.doi.org/10.5007/2177-7055.2012v33n65p33.

KOZICKI, Katya; ARAÚJO, Eduardo Borges. Um Contraponto Fraco a um Modelo Forte: o Supremo Tribunal Federal, a última palavra e o diálogo. Sequência: Estudos Jurídicos e Políticos, Florianópolis, v. 36, n. 71, p. 107, dez. 2015. ISSN 2177-7055. Disponível em: <https://periodicos. ufsc.br/index.php/sequencia/article/view/2177-7055.2015v36n71p107/30791>. Acesso em: 05 ago. 2017 .

LAFER, Celso. A reconstrução dos direitos humanos: a contribuição de Hannah Arendt. Estudos Avançados, São Paulo, v. 11, n. 30, p. 55-65, 1997. Disponível em: <http://www.scielo. br/scielo.php?script=sci_arttext\&pid=So103-40141997000200005\&lng=en\&nrm=iso $>$. Acesso em: 20 de julho 2017. http://dx.doi.org/10.159o/So103-40141997000200005. 
NASCIMENTO, Dijeison Tiago Rios; PARCA, Túlio Da Luz Lins. A importância da Lei de Acesso à Informação no desenvolvimento da cidadania participativa e no controle da res publica. Caderno Virtual do Instituto Brasiliense de Direito Público, v. 1, n. 33, p. 1-23, 2016. Disponível em: https://www.portaldeperiodicos.idp.edu.br/cadernovirtual/index. Acesso em 10 de julho de 2017.

MASQUES FILHO, Lourival Barão; BARBOSA, Cláudia Maria Barbosa. Accountability Vertical e Democratização no Judiciário: pelo fim do sufrágio restrito. Revista de Política Judiciária Gestão e Administração da Justiça, Curitiba, v. 2, n. 2, p.109 -128, Jul/Dez, 2016. Disponível em: http://indexlaw.org/index.php/revistapoliticiajudiciaria/article/view/1541/2003. Acesso em: 2 de agosto de 2017.

MICHENER, Gregory; MONCAU, Luiz Fernando Marrey; VELASCO, Rafael. Avaliação de Transparência do Estado Brasileiro e do Poder Judiciário. Rio de Janeiro: Escola de Direito do Rio de Janeiro da Fundação Getulio Vargas, Centro de Tecnologia e Sociedade, 2016. 136 p.

OEA, El Derecho de Acceso a la Informacíon em el marco jurídico Interamericano. Segunda Edición. Relatoría Especial para la Libertad de Expresión Comisión Interamericana de Derechos Humanos. 2012. Disponível em: http://www.oas.org/es/cidh/expresion/docs/ publicaciones/ACCESO\%20A\%2oLA\%2oINFORMACION\%202012\%202da\%2oedicion.pdf. Acesso em: 5 de julho de 2017.

O'DONNELL, Guillermo. Accountability horizontal e novas poliarquias. Lua Nova, São Paulo, n. 44, 1998. Disponível em: http://www.scielo.br/pdf/ln/n44/ao3n44.pdf. Acesso em: 2 agosto de 2017 .

OLIVEIRA, Gislaine Ferreira; DINARTE, Priscila Valduga. O Poder Judiciário na Sociedade em Rede: A Transparência Passiva Como Nova Forma de Democratização da Justiça. Revista de Política Judiciária, Gestão e Administração da Justiça, v. 1, n. 1, p. 276-308, 2015.

PERLINGEIRO, Ricardo. O desenvolvimento do direito de acesso a informação oficial na América Latina a partir da jurisprudência da Corte Interamericana de Direitos Humanos. In L. Neto, F. Ribeiro (Ed.). Direito e Informação na Sociedade em Rede. Porto: Faculdade de Direito da Universidade do Porto, 2016. Disponível em: SSRN: https://ssrn.com/ abstract $=2821347$. Acesso em: 5 de junho 2017.

PERUZZOTTI, Enrique; SMULOVITZ, Catalina. Social Accountability: An introduction. In: Enforcing the rule of law: Social Accountability in the New Latin American Democracies. Pittsbourg: University of Pittsbourg, 2006.

PERUZZOTI, Enrique. A POLÍTICA DE ACCOUNTABILITY SOCIAL NA AMÉRICA LATINA. Trad. Daniela Mateus de Vasconcelos. Disponível em: https://cidadhania.files.wordpress. com/2013/o6/a-polczadtica-de-accountability-social-na-america-latina.pdf. Acesso em: 5 de julho de 2017. 
PINHO, José Antonio Gomes de; SACRAMENTO, Ana Rita Silva. Accountability: já podemos traduzi-la para o português?. Revista de Administração Pública, Rio de Janeiro, v. 43, n. 6, p. 13431368, 2009. Disponível em: <http://www.scielo.br/scielo.php?script=sci_arttext\&pid=So034$76122009000600006 \& \operatorname{lng}=\mathrm{en} \& \mathrm{nrm}=\mathrm{iso}>$. Acesso em 05 agosto 2017.

ROMERO, Henrique Hugueney ; Francisco Cláudio Corrêa Meyer , SANT'ANNA. O papel das ouvidorias na comunicação pública do Poder Judiciário. Revista do Serviço Público Brasília (2), p. 185-198, abr/jun 2014. Disponível em: http://repositorio.enap.gov.br/handle/1/1371. Acesso em: 02 de agosto de 2017 .

STRECK; Lênio, TASSINARI; Clarissa; LIMA, Danilo Pereira. A relação direito e política: uma análise da atuação do judiciário na história brasileira. Revista Pensar, Fortaleza, v. 18, n. 3, pg. 737-758, 2013. Disponível em: http://periodicos.unifor.br/rpen/article/view/28o8. Acesso em: 2 de agosto de 2017 .

TAVARES NETO, José Querino; BARBOSA, Cláudia Maria. Democratização da função jurisdicional: uma análise a partir de Pierre Bourdie. Revista Faculdade Direito da UFG, v.36, n. o1, p. 6o-84, jan. / jun. 2012.

TOMIO, Fabrício Ricardo de Limas; ROBL FILHO, Ilton Norberto. Accountability e independência judiciais: uma análise da competência do Conselho Nacional de Justiça (CNJ). Rev. Sociol. Polit., Curitiba, v. 21, n. 45, p. 29-46, Mar. 2013 . Available from <http:// www.scielo.br/scielo.php?script=sci_arttext\&pid=So104-44782013000100004\&lng=en\&nrm=i so>. access on 03 Aug. 2017. http://dx.doi.org/10.159o/So104-44782013000100004.

WORLD BANK, Access to Information and Transparency in the Judiciary: A Guide to Good Practices from Latin America, 2010. Álvaro Herrero Gaspar López (ccord). Disponível em: http:// siteresources.worldbank.org/WBI/Resources/213798-1259011531325/6598384-1268250334206/ Transparency_Judiciary.pdf. Acesso em: 10 de julho de 2017. 